\title{
Stability and Hopf Bifurcation for a Delayed SIR Epidemic Model with Logistic Growth
}

\author{
Yakui Xue and Tiantian Li \\ Department of Mathematics, North University of China, Taiyuan, Shanxi 030051, China \\ Correspondence should be addressed to Yakui Xue; xyk5152@163.com
}

Received 28 August 2013; Revised 23 September 2013; Accepted 23 September 2013

Academic Editor: Massimiliano Ferrara

Copyright ( 2013 Y. Xue and T. Li. This is an open access article distributed under the Creative Commons Attribution License, which permits unrestricted use, distribution, and reproduction in any medium, provided the original work is properly cited.

\begin{abstract}
We study a delayed SIR epidemic model and get the threshold value which determines the global dynamics and outcome of the disease. First of all, for any $\tau$, we show that the disease-free equilibrium is globally asymptotically stable; when $R_{0}<1$, the disease will die out. Directly afterwards, we prove that the endemic equilibrium is locally asymptotically stable for any $\tau=0$; when $R_{0}>1$, the disease will persist. However, for any $\tau \neq 0$, the existence conditions for Hopf bifurcations at the endemic equilibrium are obtained. Besides, we compare the delayed SIR epidemic model with nonlinear incidence rate to the one with bilinear incidence rate. At last, numerical simulations are performed to illustrate and verify the conclusions.
\end{abstract}

\section{Introduction}

Many scholars have been studying the change law of things by analyzing dynamic behavior of the corresponding system [1-28]. Recently, people established some epidemic models according to many realistic factors such as delay factor, isolation, and population change. People prevent many epidemics from spreading by establishing reasonable mathematics models. In fact, many diseases have different kinds of delays when they spread, such as immunity period delay [2-4], infection period delay [5], and incubation period delay [3, 6$13,16-18,25]$. The time delay may influence the dynamics of infectious diseases. So it is necessary and useful to discuss delayed epidemic model.

Many scholars have discussed how delay affected the spread of infectious diseases. And some delays do not have an influence on transmission of epidemics [2-12]. Global properties of a delayed SIR model with temporary immunity and nonlinear incidence rate were discussed by Kyrychko and Blyuss in [2]; they considered time delay representing temporary immunity period and showed the endemic equilibrium was globally asymptotically stable, which indicated that the delay had no effect on the system with nonlinear incidence rate. And McCluskey studied the global stability for an SIR epidemic model with delay and nonlinear incidence rate [7]; he showed that the endemic equilibrium was globally asymptotically stable by using a Lyapunov function. And global stability of a delayed SIRS epidemic model with a nonmonotonic incidence rate was discussed by Muroya et al. [8], who proved that the endemic equilibrium was globally asymptotically stable. This illustrated that the delay could not affect the dynamics of the system with nonmonotonic incidence rate. At the same time, Xu and Ma studied stability of a delayed SIRS epidemic model with a nonlinear incidence rate [10]; the global asymptotic stability of system at the endemic equilibrium was proved. Besides, Yoshida and Hara discussed global stability of a delayed SIR epidemic model with density dependent birth and death rates in [11]. They investigated the stability of the endemic equilibrium, which was showed to be globally asymptotically stable. These researches above indicate delay has no effect on transmission of epidemics under certain conditions.

However, some delays impact the dynamics of system, which cause Hopf bifurcation to occur [13-20, 24, 27]. And Akkocaoğlu et al. discussed Hopf bifurcation analysis of a general nonlinear differential equation with delay in [13]. They get necessary conditions for the linear stability and Hopf bifurcation. There are also other scholars who analyze 
the existence of Hopf bifurcation in system. Hopf bifurcation analysis for a model of genetic regulatory system with delay was investigated by Wan and Zou in [14]. They analyzed the direction of the bifurcation and the stability of bifurcated periodic solutions. At the same time, density Hopf bifurcation in two SIRS dependent epidemic models was studied by Greenhalgh et al. [15], who found that Hopf bifurcation was theoretically possible but appeared not to occur for realistic parameter values. Meanwhile, Song et al. studied properties of stability and Hopf bifurcation for a HIV infection model with time delay [18] and showed that Hopf bifurcation would occur under certain conditions. However, Some professors researched how population change affected the dynamic behavior of system [21-25, 28]. Ferrara studied an Ak Solow model with a nonpositive rate of population growth [21] and analyzed how a nonpositive population growth rate hypothesis affected the dynamics of the standard Ak Solow model. At the same time, a note on the Ak Solow-Swan model with bounded population growth rate was researched by him [22]; he examined the effects of assuming a negative lower bound for the population growth rate within the SolowSwan model with Ak technology and bounded population growth rate introduced by Guerrini. Besides, he researched the Ak Solow model with logistic law technology [23] and analyzed how a logistic law technology hypothesis affected the dynamics of the standard Ak Solow model. Stability and Hopf bifurcation for a regulated logistic growth model with discrete and distributed delays was studied by Fang and Jiang [24]; they proved that the system was locally asymptotically stable in a range of the delay and Hopf bifurcation occurred as $\tau$ crossed a critical value. Enatsu et al. analyzed stability of delayed SIR epidemic models with a class of nonlinear incidence rates in [25]. In this paper, on the basis of $[23-25,27]$, we consider the incidence rate like $\beta S(t-\tau) I(t-\tau) /(1+\alpha I(t-\tau))$ and establish the following models with logistic growth, obtaining conditions for Hopf bifurcation. At the same time, the death rate due to disease and the same natural death rate of $S, I$, and $R$ are considered.

The organization of this paper is as follows. In Section 2, SIR epidemic models, their basic reproduction number, and existence of equilibrium are given. In addition, the stability and existence of Hopf bifurcation of system (2) and system (6) are discussed in detail. In Section 3, we present the numerical simulations to verify the conclusions. In Section 4, a brief discussion is given to conclude this work.

\section{The SIR Epidemic Model, the Basic Reproduction Number, and Equilibrium}

We establish the delayed SIR epidemic model. Here, $S(t)$ represents the number of individuals who are susceptible to the disease, that is, who are not yet infected at time $t$. $I(t)$ represents the number of infected individuals who are infectious and are able to spread the disease by contacting with susceptible individuals at time $t . R(t)$ represents the number of recovered individuals at time $t$.

The transfer diagram is depicted in Figure 5.
SIR epidemic model with nonlinear incidence rate is as follows:

$$
\begin{gathered}
\frac{d S}{d t}=r S\left(1-\frac{S}{K}\right)-\frac{\beta S(t-\tau) I(t-\tau)}{1+\alpha I(t-\tau)}, \\
\frac{d I}{d t}=\frac{\beta S(t-\tau) I(t-\tau)}{1+\alpha I(t-\tau)}-\left(\mu+\alpha_{1}+v\right) I, \\
\frac{d R}{d t}=v I-\mu R .
\end{gathered}
$$

In system (1), it is assumed that the population growth in susceptible host individuals is governed by the logistic growth with a carrying capacity $K>0$ as well as intrinsic birth rate constant $r>0$, where the parameters $\mu, \beta, \alpha, \alpha_{1}, k$, and $\tau$ are positive constants in which $\mu$ is the natural death rate of the population; $\beta$ is the disease transmission coefficient; $\alpha$ is the parameter which measures the psychological or inhibitory effect; $\alpha_{1}$ is the death rate due to disease; $v$ is the recovery rate and $\tau$ is the latent period of the epidemic.

For simplicity, define $\widetilde{S}(t)=S(t) / K, \widetilde{I}(t)=I(t) / K, \widetilde{R}(t)=$ $R(t) / K . \tilde{t}=\beta K t, \widetilde{r}=r / \beta K, \widetilde{\tau}=\beta K \tau, \widetilde{G}(\widetilde{I}(\tilde{t}))=G(I(t)) / K$, $\tilde{\mu}=\mu / \beta K, \widetilde{\alpha}_{1}=\alpha_{1} / \beta K, \widetilde{v}=v / \beta K, \widetilde{\alpha}=\alpha / \beta K$. When dropping the $\sim$, system (1) becomes the following system:

$$
\begin{gathered}
\frac{d S}{d t}=r S(1-S)-\frac{S(t-\tau) I(t-\tau)}{1+\alpha I(t-\tau)}, \\
\frac{d I}{d t}=\frac{S(t-\tau) I(t-\tau)}{1+\alpha I(t-\tau)}-\left(\mu+\alpha_{1}+v\right) I, \\
\frac{d R}{d t}=v I-\mu R .
\end{gathered}
$$

The initial conditions for system (2) are $S(\theta)=\varphi_{1}(\theta)$, $I(\theta)=\varphi_{2}(\theta), R(\theta)=\varphi_{3}(\theta) .\left(\varphi_{1}(\theta), \varphi_{2}(\theta), \varphi_{3}(\theta)\right) \in C_{+}=$ $C\left([-\tau, 0], \mathbf{R}_{+}^{3}\right), \varphi_{i}(0) \geq 0, i=1,2,3 . \mathbf{R}_{+}^{3}=\left\{x_{1}, x_{2}, x_{3} \in\right.$ $\left.\mathbf{R}^{3}: x_{i} \geq 0, i=1,2,3\right\}$. And the feasible region of the model with the initial condition above is

$$
\boldsymbol{\Omega}=\left\{(S, I, R) \in \mathfrak{R}_{+0}^{3} \mid S+I+R \leq 1\right\} .
$$

It is easy to show that $\Omega$ is positively invariant with respect to system (1). According to the calculation and the practical significance of the epidemic model, system (2) always has a disease-free equilibrium $E_{0}(1,0,0)$. Define the basic reproduction number as follows:

$$
R_{0}=\frac{1}{a}
$$

Let $a=\mu+\alpha_{1}+v$. If the basic reproduction number $R_{0}>$ 1 , there exists a unique endemic equilibrium $E^{*}((r \alpha-1+$ $\left.\left.\sqrt{(1-r \alpha)^{2}+4 r a \alpha}\right) / 2 r \alpha,\left(S^{*}-a\right) / a \alpha, v\left(S^{*}-a\right) / \mu a \alpha\right)$. 
SIR epidemic model with bilinear incidence rate is as follows: when $\alpha=0$, system (1) becomes

$$
\begin{gathered}
\frac{d S}{d t}=r S\left(1-\frac{S}{K}\right)-\beta S(t-\tau) I(t-\tau), \\
\frac{d I}{d t}=\beta S(t-\tau) I(t-\tau)-\left(\mu+\alpha_{1}+v\right) I, \\
\frac{d R}{d t}=v I-\mu R .
\end{gathered}
$$

After the same transformation, system (5) becomes

$$
\begin{gathered}
\frac{d S}{d t}=r S(1-S)-S(t-\tau) I(t-\tau), \\
\frac{d I}{d t}=S(t-\tau) I(t-\tau)-\left(\mu+\alpha_{1}+v\right) I, \\
\frac{d R}{d t}=v I-\mu R .
\end{gathered}
$$

System (6) always has a disease-free equilibrium $E_{0}(1,0,0)$. Define the basic reproduction number as follows:

$$
R_{0}=\frac{1}{a}
$$

Let $a=\mu+\alpha_{1}+v$. If the basic reproduction number $R_{0}>1$, there exists a unique endemic equilibrium $E^{*}(a, r(1-$ a), $\operatorname{vr}(1-a) / \mu)$.

First of all, system (2) is studied. We prove that the disease-free equilibrium is globally asymptotically stable. And the endemic equilibrium is locally asymptotically stable when $\tau \in\left[0, \tau_{0}\right)$ and is unstable when $\tau>\tau_{0}$. Meanwhile, system (2) undergoes Hopf bifurcation at $E^{*}$ when $\tau=\tau_{k}$. And it is proved that the same conclusions appear in system (6).

2.1. SIR Epidemic Model with Nonlinear Incidence Rate. In this section, we discuss the local stability of the diseasefree equilibrium in system (2) by analyzing its corresponding characteristic equation. By defining a reasonable Lyapunov function, we resolve the global dynamics of it without requiring any extra conditions. At the same time, we study the dynamics of system (2) at the endemic equilibrium $E^{*}$. And the conditions for Hopf bifurcation are get.

Theorem 1. If $R_{0}<1$, the disease-free equilibrium $E_{0}$ of system (2) is locally asymptotically stable for any $\tau$. If $R_{0}>1$, it is unstable for any $\tau$.

Proof. When $\tau \neq 0$, the characteristic equation at the diseasefree equilibrium $E_{0}$ of system (2) takes the form

$$
(\lambda+r)(\lambda+\mu)\left(\lambda+a-e^{-\lambda \tau}\right)=0 .
$$

Clearly, system (2) always has two negative real roots: $\lambda_{1}=-r$ and $\lambda_{2}=-\mu$. All other roots are given by the roots of equation

$$
\begin{gathered}
\lambda+a-e^{-\lambda \tau}=0, \\
\lambda=e^{-\lambda \tau}-a \\
R_{e}(\lambda)=e^{-R_{e}(\lambda)} \cos (\tau \operatorname{lm} \lambda)-a .
\end{gathered}
$$

Assume $R_{e}(\lambda) \geq 0$,

$$
\begin{gathered}
R_{e}(\lambda) \leq 1-a, \\
R_{e}(\lambda) \leq a\left(R_{0}-1\right) .
\end{gathered}
$$

Because $R_{0}<1$,

$$
R_{e}(\lambda)<0
$$

Therefore the disease-free equilibrium $E_{0}$ of system (2) is locally asymptotically stable.

If $R_{0}>1$, let $f(\lambda)=\lambda+a-e^{-\lambda \tau}$, because $f(0)<0$, $f(+\infty)>0$, there is one positive real root at least. As a result, the disease-free equilibrium $E_{0}$ of system (2) is unstable.

When $\tau=0$, it is easy for us to prove that the disease-free equilibrium $E_{0}$ of system (2) is locally asymptotically stable.

Theorem 2. If $R_{0}<1$, the disease-free equilibrium $E_{0}$ of system (2) is globally asymptotically stable for any $\tau$.

Proof. For $t>0$, define a differentiable Lyapunov function

$$
V=V_{1}+V_{2}
$$

Obviously $V \geq 0$,

$$
\begin{gathered}
V_{1}=I \\
V_{2}=\int_{t-\tau}^{t} \frac{S(t-\tau)}{1+\alpha I(t-\tau)} d \theta .
\end{gathered}
$$

Calculating the derivative of $V(t)$ along positive solutions of system (2), it follows that

$$
\begin{gathered}
\dot{V}=\dot{V}_{1}+\dot{V}_{2}, \\
\dot{V}=\frac{S I}{1+\alpha I}-a I .
\end{gathered}
$$

Because $S \leq 1,1 /(1+\alpha I)<1$. And when $R_{0}<1, \dot{V} \leq(1-a) I$,

$$
\begin{gathered}
\dot{V} \leq a\left(R_{0}-1\right) I, \\
\dot{V} \leq 0 .
\end{gathered}
$$

While $\dot{V}=0$, if and only if, $S=1, I=0, R=0$. For all $t$, it is easy to show that $E_{0}$ is the largest invariant subset of the set $\{(S, I, R): \dot{V}=0\}$. Because of LaSalle's invariance principle, the disease-free equilibrium $E_{0}$ of system (2) is globally asymptotically stable. This completes the proof. 
Theorem 3. If $R_{0}>1$, the endemic equilibrium $E^{*}$ is asymptotically stable when $\tau \in\left[0, \tau_{0}\right)$; Hopf bifurcation arises at $E^{*}$ when $\tau$ passes through a sequence of critical values $\tau_{k}$ in system (2).

Proof. The characteristic equation at the endemic equilibrium $E^{*}$ is

$$
\begin{aligned}
\lambda^{2} & +\left(a p-q\left(2 r S^{*}-r\right)-q \lambda\right) e^{-\lambda \tau} \\
& +\left(a+2 r S^{*}-r+p\right) \lambda+a\left(2 r S^{*}-r\right)=0 .
\end{aligned}
$$

Here $I^{*} /\left(1+\alpha I^{*}\right)=p, S^{*} /\left(1+\alpha I^{*}\right)^{2}=q$.

When $\tau=0$, the characteristic equation at the endemic equilibrium $E^{*}$ is

$$
\begin{aligned}
& \lambda^{2}+\left(a+2 r S^{*}-r+p-q\right) \lambda+a p \\
& \quad-q\left(2 r S^{*}-r\right)+a\left(2 r S^{*}-r\right)=0 .
\end{aligned}
$$

Here let

$$
\begin{gathered}
m_{1}=a+2 r S^{*}-r+p-q, \\
m_{2}=a p-q\left(2 r S^{*}-r\right)+a\left(2 r S^{*}-r\right) .
\end{gathered}
$$

Because $r-r S^{*}=p, a>q$, and $r>p$, order $g=r S^{*}$. One has

$$
\begin{aligned}
& m_{1}=a+r-p-q>0, \\
& m_{2}=a g-q g+q r>0 .
\end{aligned}
$$

According to Hurwitz criterion, the endemic equilibrium $E^{*}$ of system (2) is locally asymptotically stable.

When $\tau \neq 0$, let

$$
\begin{gathered}
h_{1}=a p-q\left(2 r S^{*}-r\right), \quad h_{2}=q, \\
h_{3}=a+2 r S^{*}-r+p, \quad h_{4}=a\left(2 r S^{*}-r\right) .
\end{gathered}
$$

The characteristic equation at the endemic equilibrium $E^{*}$ of system (2) takes the form

$$
\lambda^{2}+\left(h_{1}-h_{2} \lambda\right) e^{-\lambda \tau}+h_{3} \lambda+h_{4}=0 .
$$

Suppose that $\lambda=i \omega$ is a root of (21). On substituting $\lambda=i \omega$, we derive that

$$
\begin{gathered}
-\omega^{2}+\left(h_{1}-h_{2} \omega i\right)((\cos (\omega \tau)-i \sin (\omega \tau))) \\
+h_{3} \omega i+h_{4}=0 .
\end{gathered}
$$

Separating real and imaginary parts, it follows that

$$
\begin{gathered}
-\omega^{2}+h_{1} \cos (\omega \tau)-h_{2} \omega \sin (\omega \tau)+h_{4}=0, \\
-h_{1} \sin (\omega \tau)-h_{2} \omega \cos (\omega \tau)+h_{3} \omega=0 .
\end{gathered}
$$

Squaring and adding equations the both, then we have

$$
\omega^{4}+\left(h_{3}^{2}-2 h_{4}^{2}-h_{2}^{2}\right) \omega^{2}+h_{4}^{2}-h_{1}^{2}=0 .
$$

Letting $z=\omega^{2}$, then (24) becomes

$$
z^{2}+\left(h_{3}^{2}-2 h_{4}^{2}-h_{2}^{2}\right) z+h_{4}^{2}-h_{1}^{2}=0 .
$$

Here $h_{4}^{2}-h_{3}^{2}=\left((a-q)\left(2 r S^{*}-r\right)+a p\right)\left((a+q)\left(2 r S^{*}-r\right)-a p\right)$. It is easy to show that $(a-q)\left(2 r S^{*}-r\right)+a p>0$. One has

$$
\begin{gathered}
(a+q)\left(2 r S^{*}-r\right)-a p+q\left(2 r S^{*}-r\right)-a p \\
=a(3 g-2 r)+q(2 g-r) .
\end{gathered}
$$

So when $r>2 g, a(3 g-2 r)+q(2 g-r)<0$. Then there is a unique positive $z$ satisfying (25). That is, there is a single pair of purely imaginary roots $\pm i \omega_{0}$ of (21).

From (23), we get the corresponding $\tau_{k}>0$ such that the characteristic equation (21) has a pair of purely imaginary roots:

$$
\begin{aligned}
\tau_{k}= & \frac{1}{\omega_{0}} \arccos \frac{\left(\omega_{0}\right)^{2} h_{1}-h_{1} h_{4}+h_{2} h_{3}\left(\omega_{0}\right)^{2}}{h_{1}^{2}+h_{2} \omega_{0}^{2}} \\
& +\frac{2 k \pi}{\omega_{0}}, \quad k=1,2,3, \ldots
\end{aligned}
$$

Next we show

$$
\left.\frac{d(\operatorname{Re} \lambda)}{d \tau}\right|_{\tau=\tau_{k}}>0 .
$$

This will signify that there exists at least one eigenvalue with positive real part for $\tau>\tau_{k}$. Differentiating (21) with respect to $\tau$, we will obtain

$$
\begin{gathered}
2 \lambda \frac{d \lambda}{d \tau}-h_{2} \frac{d \lambda}{d \tau} e^{-\lambda \tau}+\left(h_{1}-h_{2} \lambda\right) e^{-\lambda \tau} \\
\times\left(-\frac{d \lambda}{d \tau} \tau-\lambda\right)+h_{3} \frac{d \lambda}{d \tau}=0 .
\end{gathered}
$$

Therefore

$$
\begin{aligned}
\left(\frac{d \lambda}{d \tau}\right)^{-1}= & \frac{2 \lambda+h_{3}-h_{2} e^{-\lambda \tau}-\tau\left(h_{1}-h_{2} \lambda\right) e^{-\lambda \tau}}{\left(h_{1}-h_{2} \lambda\right) \lambda e^{-\lambda \tau}} \\
= & \frac{2 \lambda+h_{3}}{\lambda\left(h_{1}-h_{2} \lambda\right) e^{-\lambda \tau}}-\frac{h_{2} e^{-\lambda \tau}}{\left(h_{1}-h_{2} \lambda\right) e^{-\lambda \tau} \lambda}-\frac{\tau}{\lambda} \\
= & \frac{2 \lambda+h_{3}}{-\lambda\left(\lambda^{2}+h_{3} \lambda+h_{4}\right)}-\frac{h_{2}}{\lambda\left(h_{1}-h_{2} \lambda\right)}-\frac{\tau}{\lambda}, \\
& \operatorname{sign}\left\{\left.\frac{d(\operatorname{Re} \lambda)}{d \tau}\right|_{\tau=\tau_{k}}\right\} \\
= & \operatorname{sign}\left\{\left.\operatorname{Re}\left(\frac{d \lambda}{d \tau}\right)^{-1}\right|_{\lambda=i \omega_{0}}\right\}
\end{aligned}
$$




$$
\begin{gathered}
=\operatorname{sign}\left\{\left.\operatorname{Re}\left[\frac{2 \lambda+h_{3}}{-\lambda\left(\lambda^{2}+h_{3} \lambda+h_{4}\right)}\right]\right|_{\lambda=i \omega_{0}}\right\} \\
\left.-\left.\operatorname{Re}\left[\frac{h_{2}}{\lambda\left(h_{1}-h_{2} \lambda\right)}\right]\right|_{\lambda=i \omega_{0}}\right\} \\
=\operatorname{sign}\left\{\operatorname { R e } \left[\frac{2 \omega_{0}^{2}-h_{3} \omega_{0} i}{\omega_{0}^{2}\left(\omega_{0}^{2}-h_{4}-h_{3} \omega_{0} i\right)}\right.\right. \\
\left.=\operatorname{sign}\left\{\frac{2\left(\omega_{0}^{2}-h_{4}\right)+h_{3}^{2}}{\omega_{0}^{2}\left(h_{1}-h_{2} \omega_{0} i\right)}\right]\right\} \\
=\operatorname{sign}\left\{\frac{h_{2}^{2} \omega_{0}^{4}+2 h_{1}^{2} \omega_{0}^{2}+h_{3}^{2} h_{1}^{2}-2 h_{4} h_{1}^{2}-h_{2}^{2} h_{4}^{2}}{\left(\left(\omega_{0}^{2}-h_{4}\right)^{2}+h_{3}^{2} \omega_{0}^{2}\right)\left(h_{1}^{2}+h_{2}^{2} \omega_{0}^{2}\right)}\right\} .
\end{gathered}
$$

Here, we will show $h_{3}^{2} h_{1}^{2}-2 h_{4} h_{1}^{2}-h_{2}^{2} h_{4}^{2}>0$. Let $h_{3}^{2} h_{1}^{2}-2 h_{4} h_{1}^{2}-$ $h_{2}^{2} h_{4}^{2}=H$.

One has

$$
\begin{aligned}
H= & (g-r)^{2} a^{4}+2(r-g)^{3}+2 q(2 g-r)(g-r) a^{3} \\
& +\left(g^{2}(g-r)^{2}+q\left(4 r^{2}(r-4 g)(5 r-2 g)\right)\right) a^{2} \\
& +\left(2 g^{2} q(2 g-r)(g-r)\right. \\
& \left.+q^{2}\left(8 g^{2}(2 r-g)+2 r^{2}(r-5 g)\right)\right) a \\
& +g^{2} q^{2}(2 g-r)^{2} .
\end{aligned}
$$

According to the formula above, if $r \geq 5 g, H>0$, that is, when

$$
\frac{r \alpha-1+\sqrt{(1-r \alpha)^{2}+4 r a \alpha}}{2 r \alpha}<\frac{1}{5} .
$$

We can derive $d(\operatorname{Re} \lambda) /\left.d \tau\right|_{\tau=\tau_{k}}>0$ when $0<a<$ 0.2 . Therefore, the transversality condition holds and the conditions for Hopf bifurcation are satisfied at $\tau=\tau_{k}$ in system (2).

2.2. SIR Epidemic Model with Bilinear Incidence Rate. Using the same methods in system (2), we can prove that the disease-free equilibrium in system (6) is globally asymptotically stable for any $\tau$. Here the proof is ignored. And we only study the dynamics of system (6) at the endemic equilibrium $E^{*}$.

Theorem 4. If $R_{0}>1$, the endemic equilibrium $E^{*}$ is asymptotically stable when $\tau \in\left[0, \tau_{0}\right)$; system (6) undergoes Hopf bifurcation at $E^{*}$ when $\tau=\tau_{k}$.
Proof. The characteristic equation at the endemic equilibrium $E^{*}$ of system (6) is

$$
\begin{gathered}
\lambda^{2}+\left(r S^{*}+a I^{*}-2 r\left(S^{*}\right)^{2}+\left(I^{*}-S^{*}\right) \lambda\right) e^{-\lambda \tau} \\
+\left(a+2 r S^{*}-r\right) \lambda+2 r a S^{*}-r a=0 .
\end{gathered}
$$

When $\tau=0$, the characteristic equation at the endemic equilibrium $E^{*}$ is

$$
\begin{gathered}
\lambda^{2}+\left(a+2 r S^{*}-r+I^{*}-S^{*}\right) \lambda+2 r a S^{*} \\
-r a+r S^{*}+a I^{*}-2 r\left(S^{*}\right)^{2}=0 .
\end{gathered}
$$

Because

$$
\begin{gathered}
a=S^{*}, \quad I^{*}=r(1-a), \\
a+2 r S^{*}-r+I^{*}-S^{*}=r a>0, \\
2 r a S^{*}-r a+r S^{*}+a I^{*}-2 r\left(S^{*}\right)^{2} \\
=\operatorname{ar}(1-a) r a^{2}\left(R_{0}-1\right)>0,
\end{gathered}
$$

the endemic equilibrium $E^{*}$ of system (6) is locally asymptotically stable. When $\tau \neq 0$, let

$$
\begin{gathered}
h_{1}=r S^{*}+a I^{*}-2 r\left(S^{*}\right)^{2}=2 a r-3 r a^{2}, \\
h_{2}=I^{*}-S^{*}=r-r a-a, \\
h_{3}=a+2 r S^{*}-r=a+2 r a-r, \\
h_{4}=2 r a S^{*}-r a=2 r a^{2}-r a .
\end{gathered}
$$

The characteristic equation at the endemic equilibrium $E^{*}$ of system (6) will become

$$
\lambda^{2}+\left(h_{1}+h_{2} \lambda\right) e^{-\lambda \tau}+h_{3} \lambda+h_{4}=0
$$

Let $\lambda=i \omega$; using the same methods in system (2), we can obtain the equation with $\omega$, as follows:

$$
\omega^{4}+\left(h_{3}^{2}-2 h_{4}-h_{2}^{2}\right) \omega^{2}+h_{4}^{2}-h_{1}^{2}=0 \text {. }
$$

Order $z=\omega^{2} ;(38)$ becomes

$$
\begin{gathered}
z^{2}+\left(h_{3}^{2}-2 h_{4}-h_{2}^{2}\right) z+h_{4}^{2}-h_{1}^{2}=0, \\
h_{4}^{2}-h_{1}^{2}=-r^{2} a^{2}(5 a-3)(a-1) .
\end{gathered}
$$

We know $a<1$. When $a<3 / 5, h_{4}^{2}-h_{1}^{2}<0$. That is, there is a single pair of purely imaginary roots $\pm i \omega_{0}$ of (39). At the same time, $\tau_{k}$ can be gotten:

$$
\begin{array}{r}
\tau_{k}=\frac{1}{\omega_{0}} \arccos \left(\frac{\omega_{0}^{2}-h_{1}-h_{1} h_{4}-h_{2} h_{3} \omega_{0}^{2}}{h_{1}^{2}+h_{2}^{2} \omega_{0}^{2}}\right)+\frac{2 k \pi}{\omega_{0}}, \\
k=1,2,3, \ldots .
\end{array}
$$




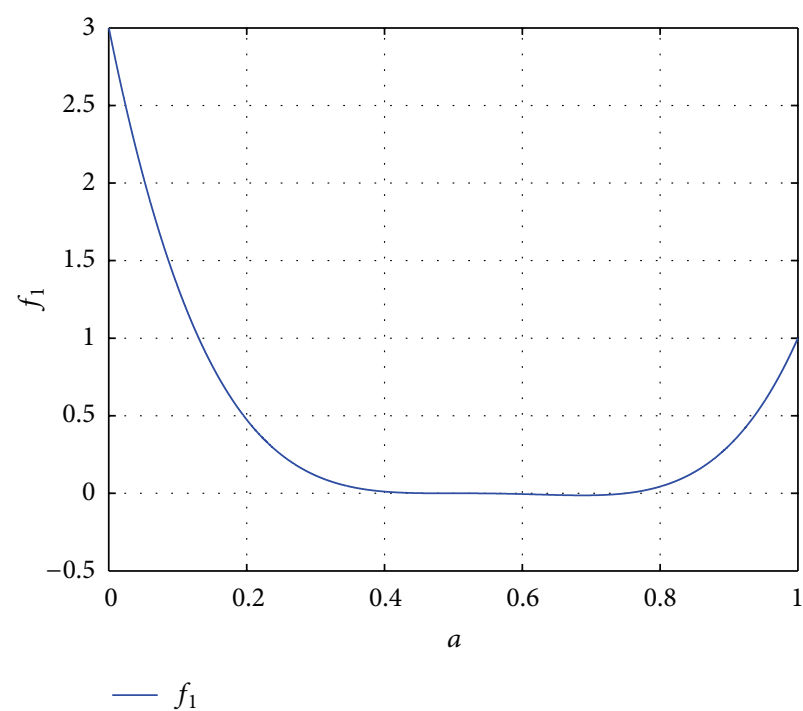

(a)

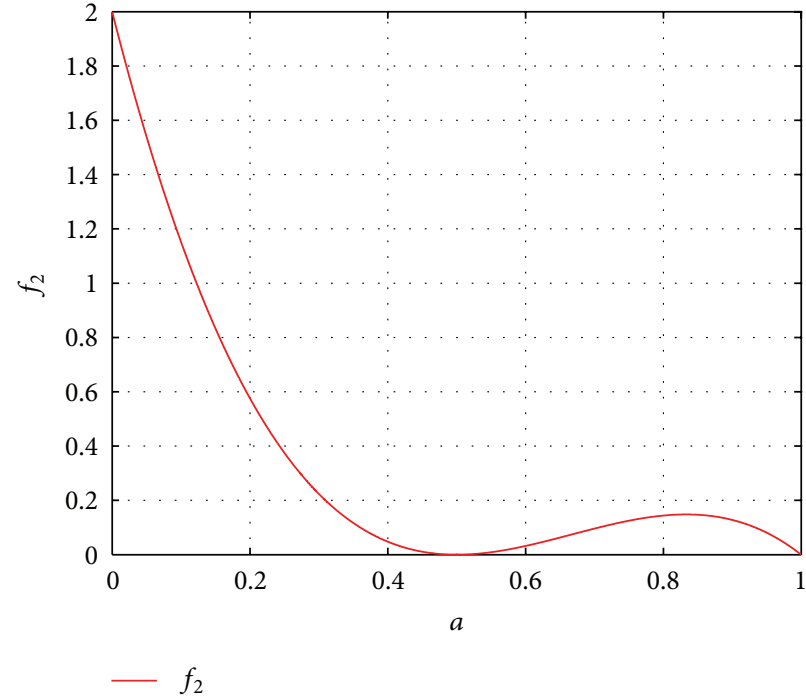

(b)

Figure 1: The graphics of $f_{1}$ and $f_{2}$.

And then

$$
\begin{aligned}
& \left(\frac{d \lambda}{d \tau}\right)^{-1}=\frac{2 \lambda+h_{3}}{\lambda\left(h_{1}+h_{2}\right) e^{-\lambda \tau}}+\frac{h_{2}}{\lambda\left(h_{1}+h_{2} \lambda\right)}-\frac{\tau}{\lambda}, \\
& \operatorname{sign}\left\{\left.\frac{d(\operatorname{Re} \lambda)}{d \tau}\right|_{\tau=\tau_{k}}\right\} \\
& \quad=\operatorname{sign}\left\{\left.\operatorname{Re}\left(\frac{d \lambda}{d \tau}\right)^{-1}\right|_{\lambda=i \omega_{0}}\right\}, \\
& \left.\operatorname{Re}\left(\frac{d \lambda}{d \tau}\right)^{-1}\right|_{\lambda=i \omega_{0}} \\
& =\frac{h_{2}^{2} \omega^{4}+2 h_{1}^{2} \omega^{2}+h_{1}^{2} h_{3}^{2}-2 h_{1}^{2} h_{4}-h_{2}^{2} h_{4}^{2}}{h_{1}^{2}+h_{2}^{2} \omega^{2}} .
\end{aligned}
$$

Let $G=h_{1}^{2} h_{3}^{2}-2 h_{1}^{2} h_{4}-h_{2}^{2} h_{4}^{2}, G=\left(36 a^{6}-72 a^{5}+60 a^{4}-22 a^{3}+\right.$ $\left.3 a^{2}\right) r^{4}+\left(-8 a^{6}+16 a^{5}-10 a^{4}+2 a^{3}\right) r^{3}+\left(5 a^{6}-8 a^{5}+3 a^{4}\right) r^{2}$. Order

$$
\begin{aligned}
& f_{1}=a^{2}\left(36 a^{4}-72 a^{3}+60 a^{2}-22 a+3\right), \\
& f_{2}=a^{3}\left(-8 a^{3}+16 a^{2}-10 a+2\right), \\
& f_{3}=5 a^{6}-8 a^{5}+3 a^{4}, \quad f_{3}=a^{4}(5 a-3)(a-1) .
\end{aligned}
$$

Obviously, $r>0$. When $a<3 / 5, f_{3}>0$. At the same time, if $0 \leq a \leq 0.5, f_{1}>0$ and $f_{2}>0$ in theory. In addition, the conclusion is also illustrated by the graphics which show the trends of the functions. See Figures $1(\mathrm{a})$ and $1(\mathrm{~b})$.

In a word, when $0 \leq a \leq 0.5, G>0$. Therefor, $d(\operatorname{Re} \lambda) /\left.d \tau\right|_{\tau=\tau_{k}}>0$. That is, the transversality condition holds and the conditions for Hopf bifurcation are satisfied at $\tau=\tau_{k}$ in system (6). Here, we can find that conditions for Hopf bifurcation become weaker in system (6) than that in system
(2). It means that system (6) undergoes Hopf bifurcation at $E^{*}$ when $\tau=\tau_{k}$ easily.

\section{The Numerical Simulations}

In this section, we study system (1) and system (5) numerically. According to the different dates that can reflect the actual situation, we get the different simulations to prove our conclusions obviously.

3.1. The Numerical Simulations of System (1). The disease-free equilibrium $E_{0}$ of system (1) is globally asymptotically stable.

Let $K=90, \beta=0.005, \mu=0.035, \alpha_{1}=0.23, v=0.2$, $r=0.15, \tau=1, \alpha=0.13$; here $R_{0}=0.9677$; see Figure 2(a).

When $R_{0}>1$, the dynamics of system (1) are shown by the following simulations.

Let $K=20, \beta=0.054, \mu=0.0540, \alpha_{1}=0.0162, \alpha=$ $0.013, v=0.0324$, and $r=0.0216$; here $R_{0}=10.5263$. When $\tau=0$, the endemic equilibrium $E^{*}$ is asymptotically stable; see Figure 2(b).

When $\tau=0.0561<\tau_{0}=0.6461$, the endemic equilibrium $E^{*}$ is also asymptotically stable; see Figures 2(c) and 2(d).

When $\tau=0.6651>\tau_{0}=0.6461$, the endemic equilibrium $E^{*}$ is unstable, and the Hopf bifurcation arises at $E^{*}$; see Figures 2(e)-2(h).

3.2. The Numerical Simulations of System (5). When $R_{0}<$ 1 , the disease-free equilibrium $E_{0}$ of system (5) is globally asymptotically stable.

Let $K=100, \beta=0.0015, \mu=0.0175, \alpha_{1}=0.055, v=$ 0.08 , and $r=0.125$; here $R_{0}=0.9836$; see Figure 3(a).

When $R_{0}>1$, the dynamics of system (5) are showed by the following simulations. 

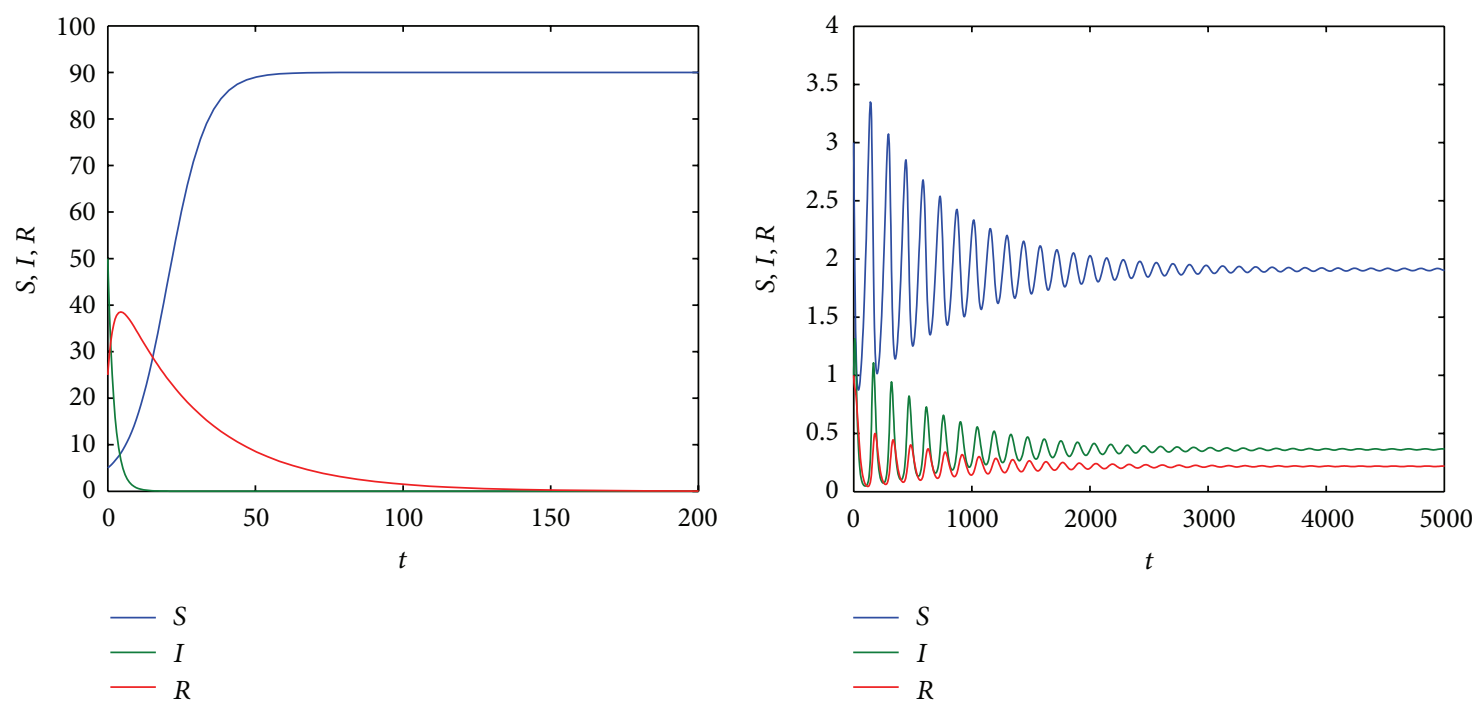

(a)

(b)
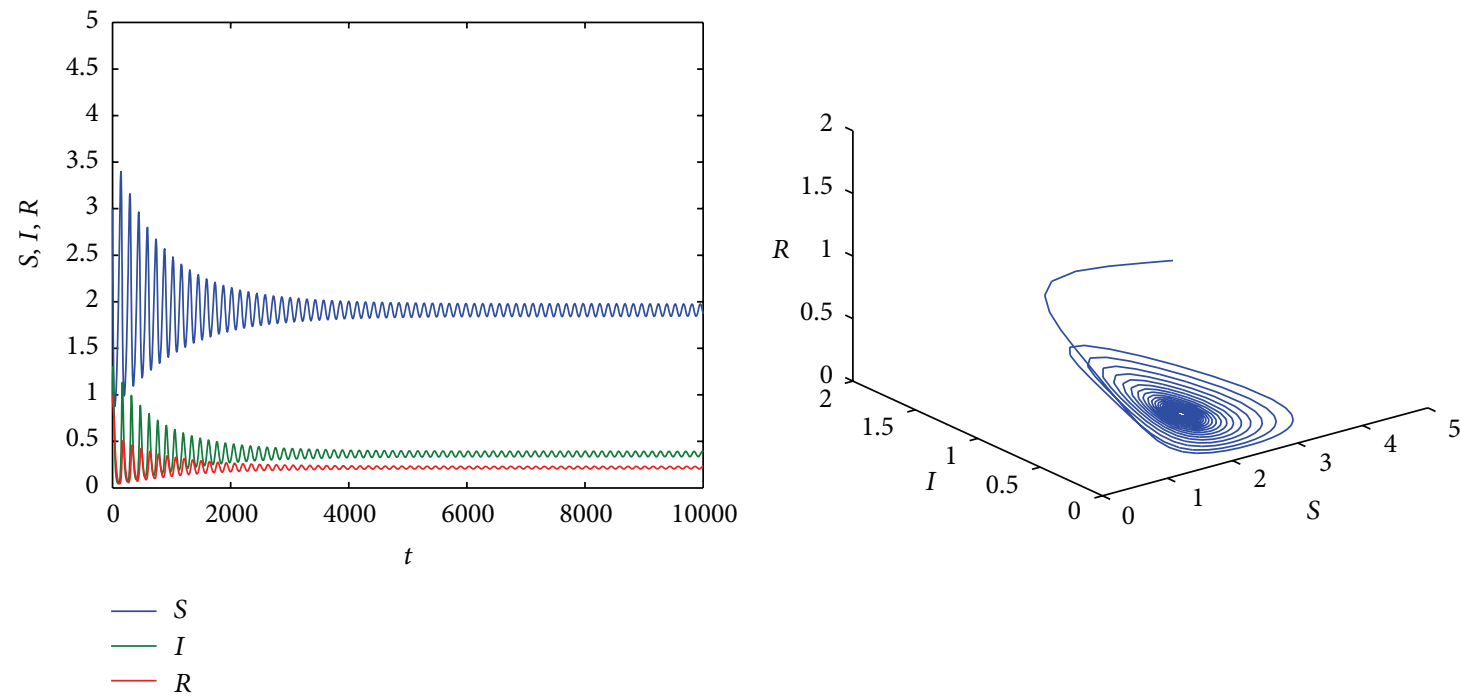

(c)

(d)
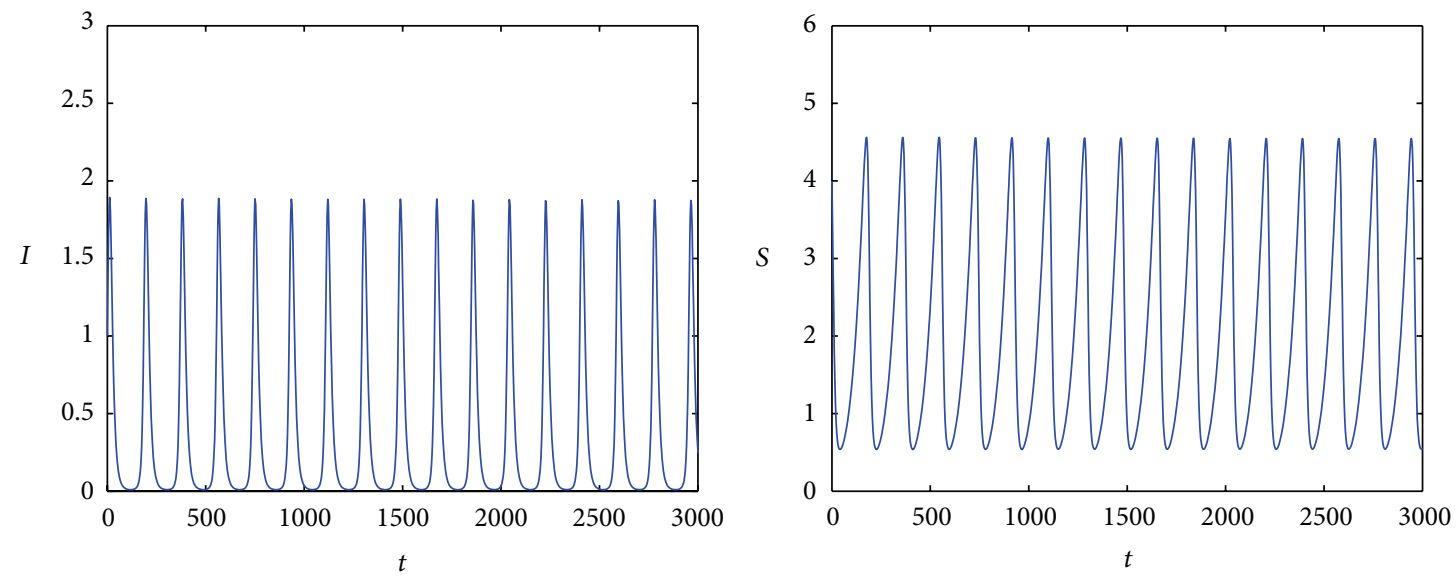

$-I$

$-S$

(e)

(f)

FIGURE 2: Continued. 


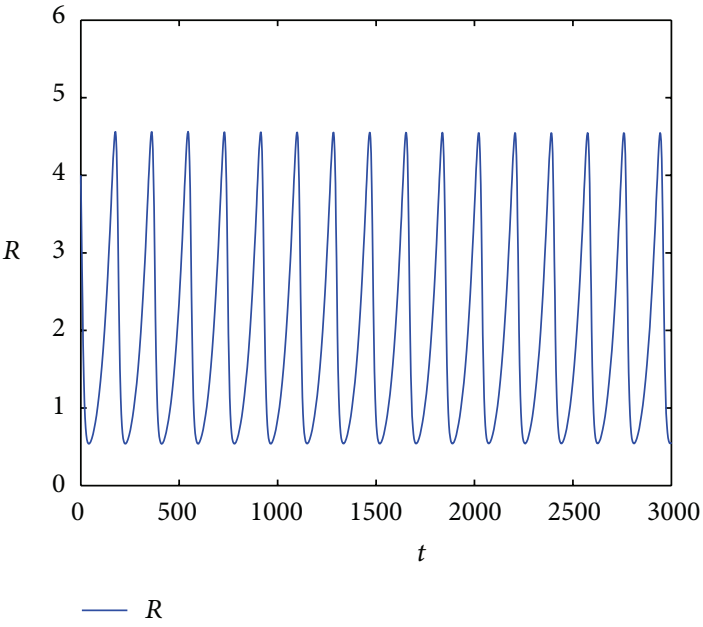

(g)

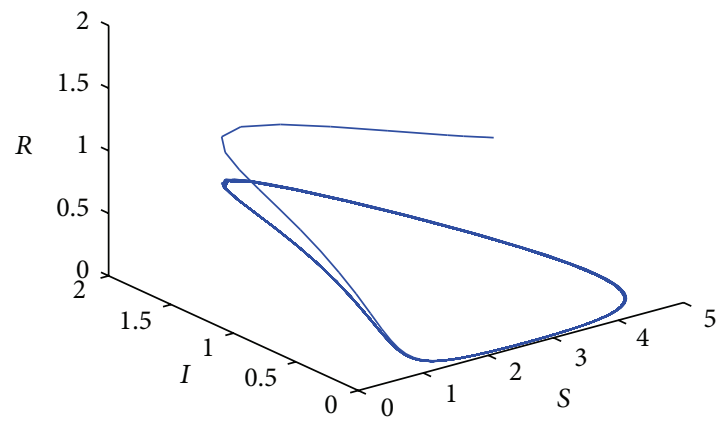

(h)

FIGURE 2: The numerical simulation graphics of system (1).

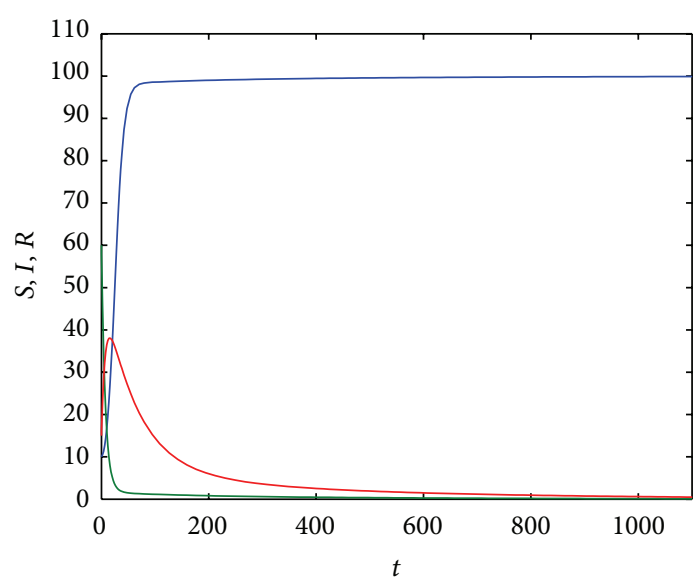

$-S$
$-I$
$-\quad R$

(a)

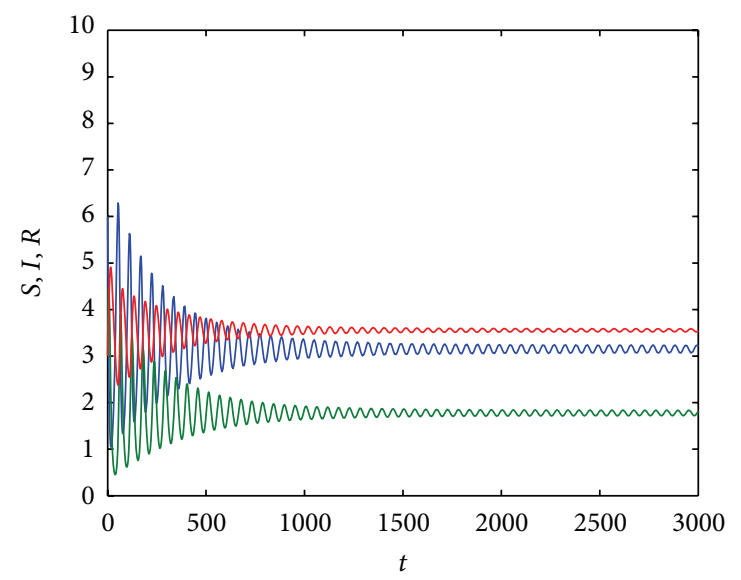

$S$
$-\quad I$
$-\quad R$

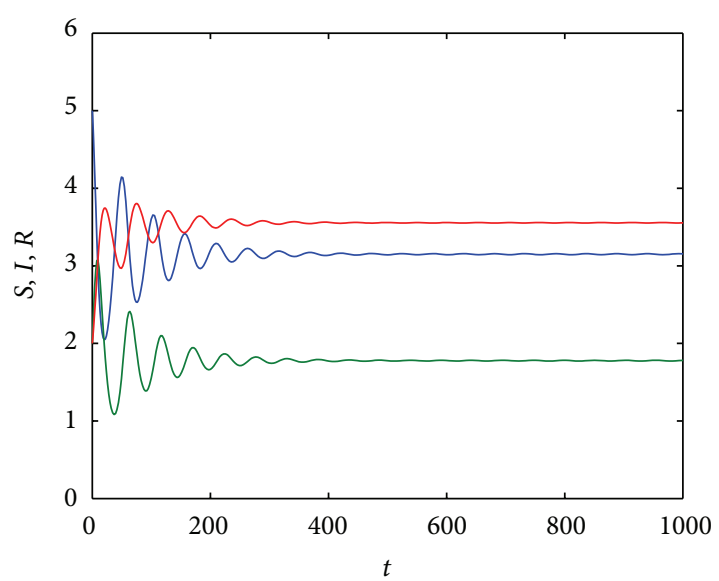

$-S$
$-I$
$-R$

(b)

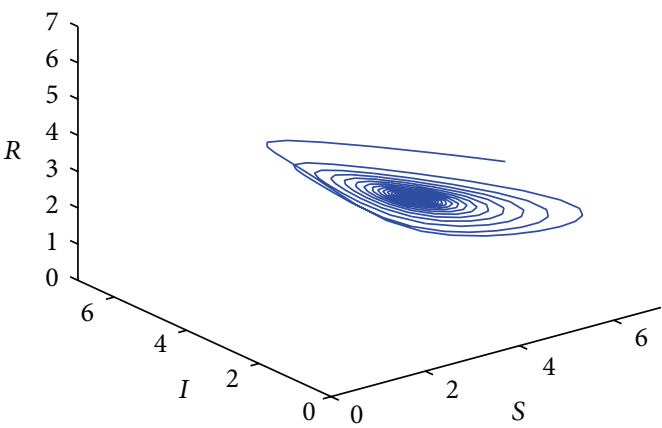

(d)

Figure 3: Continued. 


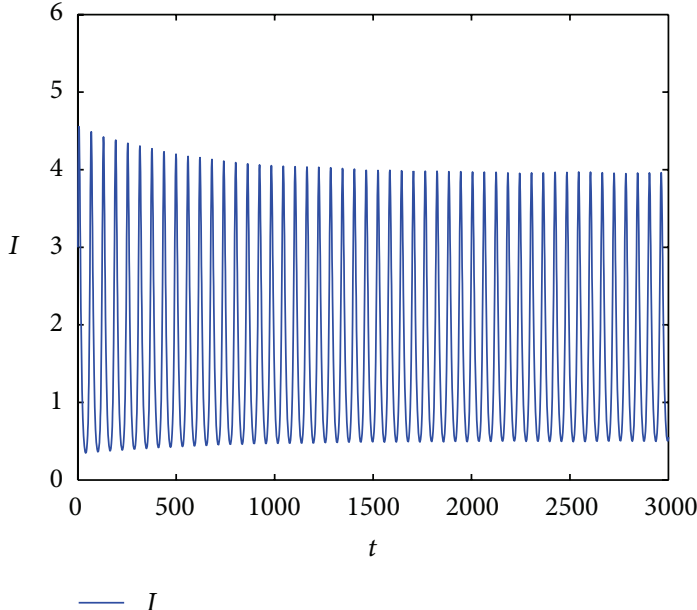

(e)

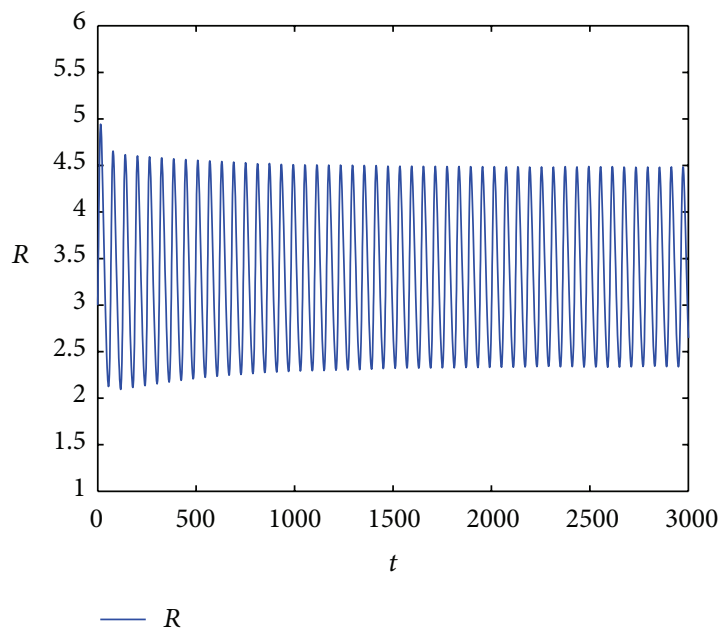

(g)

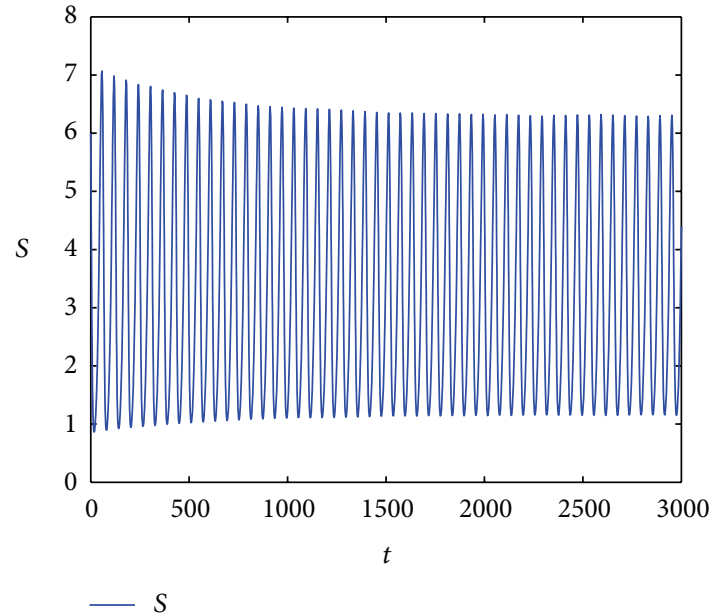

(f)

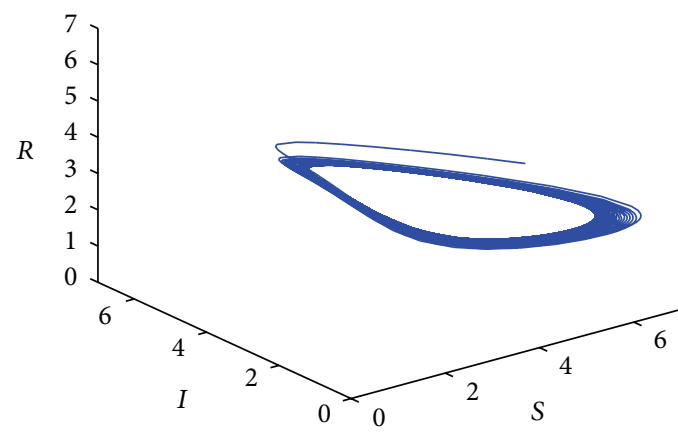

(h)

FIGURE 3: The numerical simulation graphics of system (5).

Let $K=15, \beta=0.05, \mu=0.0375, \alpha_{1}=0.0450, v=0.0750$, and $r=0.112$; here $R_{0}=4.7619$.

When $\tau=0$, the endemic equilibrium $E^{*}$ is asymptotically stable; see Figure 3(b).

When $\tau=0.6811<\tau_{0}=0.9411$, the endemic equilibrium $E^{*}$ is also asymptotically stable; see Figures 3(c) and $3(\mathrm{~d})$.

When $\tau=1.0011>\tau_{0}=0.9411$, the endemic equilibrium $E^{*}$ is unstable, and the Hopf bifurcation arises at $E^{*}$; see Figures 3(e)-3(h).

Besides, when $\alpha_{1}$ increases, $R_{0}$ will decrease. Let $K=20$, $\beta=0.054, \mu=0.0540, \alpha=0.013, v=0.0324, r=0.0216, \tau=$ 0.6651 . We can get the changing trends of $R_{0}$ as $\alpha_{1}$ changes in system (1). Obviously, there exists $\alpha_{1}^{*}$ such that $R_{0}=1$. That is, if $\alpha_{1}>\alpha_{1}^{*}$, the disease will die out.

At the same time, let $K=15, \beta=0.05, \mu=0.0375$, $v=0.0750, r=0.1125, \tau=1.0011$. We can get the changing trends of $R_{0}$ as $\alpha_{1}$ changes in system (5). Obviously, there exists $\alpha_{1}^{*}$ such that $R_{0}=1$. That is, if $\alpha_{1}>\alpha_{1}^{*}$, the disease will die out.

See Figures 4(a) and 4(b).

\section{Discussions}

In this paper, we investigate the dynamics of SIR epidemic models with the logistic growth of population of susceptible individuals. The incidence rate like $\beta S(t-\tau) I(t-\tau) /(1+$ $\alpha I(t-\tau))$ is considered here. In addition, the death rate due to disease and the same natural death rate of $S, I$, and $R$ are considered in two systems. We prove that the disease-free equilibrium is globally asymptotically stable when the basic reproduction number is less than unity for any delay $\tau$ and the endemic equilibrium is locally asymptotically stable when the basic reproduction number is greater than unity for $\tau=0$ in system (2) and system (6), respectively. At the same time, when $\tau \neq 0$, the sufficient conditions for the Hopf bifurcations are obtained, and the periodic solution will occur in the two systems. From the biological point of view, the delay here has influence on the transmission of the infectious diseases. That is, the delay is harmful. Besides, the conditions for Hopf bifurcations in system (2) are different from those in system (6). The conditions for Hopf bifurcation become weaker in system (6) than those in system (2). Therefore, according to 


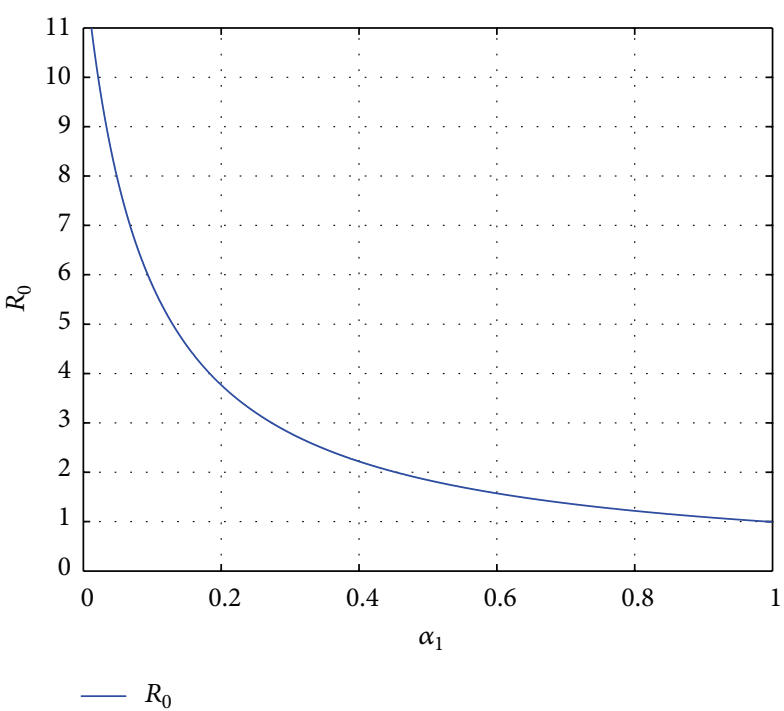

(a)

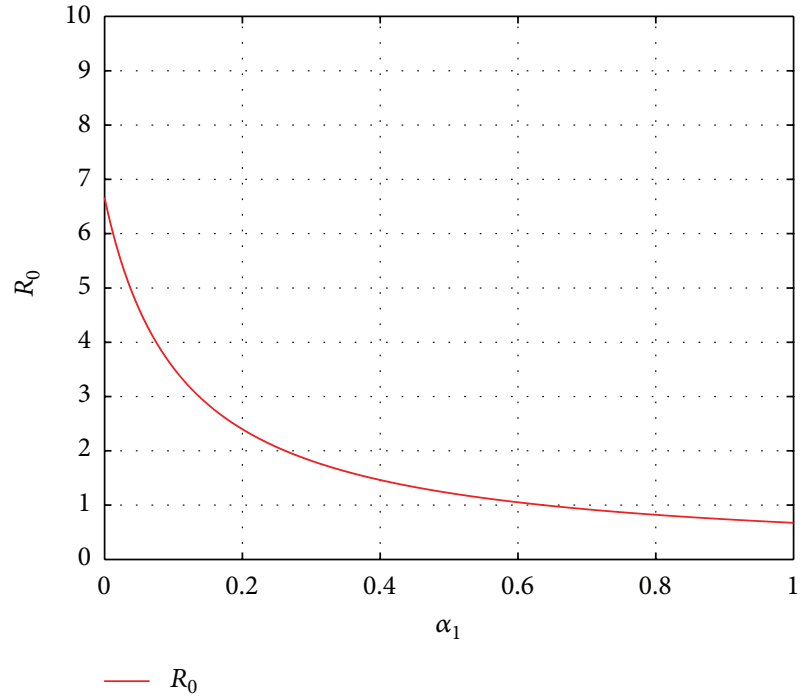

(b)

FIGURE 4: The numerical simulation graphics of $R_{0}$.

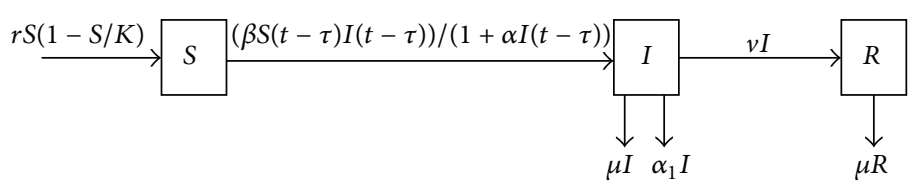

Figure 5

the different situations, people should take different measures to control diseases.

\section{Acknowledgments}

This work is supported by the National Science Foundation of China (10471040) and the National Sciences Foundation of Shanxi Province (2009011005-1).

\section{References}

[1] M. Ferrara, F. Munteanu, C. Udrişte, and D. Zugrăvescu, "Controllability of a nonholonomic macroeconomic system," Journal of Optimization Theory and Applications, vol. 154, no. 3, pp. 1036-1054, 2012.

[2] Y. N. Kyrychko and K. B. Blyuss, "Global properties of a delayed SIR model with temporary immunity and nonlinear incidence rate," Nonlinear Analysis: Real World Applications, vol. 6, no. 3, pp. 495-507, 2005.

[3] B. K. Mishra and D. K. Saini, "SEIRS epidemic model with delay for transmission of malicious objects in computer network," Applied Mathematics and Computation, vol. 188, no. 2, pp. 14761482, 2007.

[4] L. S. Wen and X. F. Yang, "Global stability of a delayed SIRS model with temporary immunity," Chaos, Solitons \& Fractals, vol. 38, no. 1, pp. 221-226, 2008.

[5] Y. Z. Pei, S. Li, C. Li, and S. Chen, "The effect of constant and pulse vaccination on an SIR epidemic model with infectious period," Applied Mathematical Modelling, vol. 35, no. 8, pp. 3866-3878, 2011.

[6] H. M. Wei, X. Z. Li, and M. Martcheva, "An epidemic model of a vector-borne disease with direct transmission and time delay," Journal of Mathematical Analysis and Applications, vol. 342, no. 2, pp. 895-908, 2008.

[7] C. C. McCluskey, "Global stability for an SIR epidemic model with delay and nonlinear incidence," Nonlinear Analysis: Real World Applications, vol. 11, no. 4, pp. 3106-3109, 2010.

[8] Y. Muroya, Y. Enatsu, and Y. Nakata, "Global stability of a delayed SIRS epidemic model with a non-monotonic incidence rate," Journal of Mathematical Analysis and Applications, vol. 377, no. 1, pp. 1-14, 2011.

[9] Z. Jin, Z. E. Ma, and M. A. Han, "Global stability of an SIRS epidemic model with delays," Acta Mathematica Scientia, vol. 26, no. 2, pp. 291-306, 2006.

[10] R. Xu and Z. E. Ma, "Stability of a delayed SIRS epidemic model with a nonlinear incidence rate," Chaos, Solitons \& Fractals, vol. 41, no. 5, pp. 2319-2325, 2009.

[11] N. Yoshida and T. Hara, "Global stability of a delayed SIR epidemic model with density dependent birth and death rates," Journal of Computational and Applied Mathematics, vol. 201, no. 2, pp. 339-347, 2007.

[12] T. L. Zhang and Z. D. Teng, "Global behavior and permanence of SIRS epidemic model with time delay," Nonlinear Analysis: Real World Applications, vol. 9, no. 4, pp. 1409-1424, 2008.

[13] H. Akkocaoğlu, H. Merdan, and C. Çelik, "Hopf bifurcation analysis of a general non-linear differential equation with delay," 
Journal of Computational and Applied Mathematics, vol. 237, no. 1, pp. 565-575, 2013.

[14] A. Y. Wan and X. F. Zou, "Hopf bifurcation analysis for a model of genetic regulatory system with delay," Journal of Mathematical Analysis and Applications, vol. 356, no. 2, pp. 464476, 2009.

[15] D. Greenhalgh, Q. J. A. Khan, and F. I. Lewis, "Hopf bifurcation in two SIRS density dependent epidemic models," Mathematical and Computer Modelling, vol. 39, no. 11-12, pp. 1261-1283, 2004.

[16] F. F. Zhang, Z. Jin, and G. Q. Sun, "Bifurcation analysis of a delayed epidemic model," Applied Mathematics and Computation, vol. 216, no. 3, pp. 753-767, 2010.

[17] T. L. Zhang, J. L. Liu, and Z. D. Teng, "Stability of Hopf bifurcation of a delayed SIRS epidemic model with stage structure," Nonlinear Analysis: Real World Applications, vol. 11, no. 1, pp. 293-306, 2010.

[18] X. Song, X. Zhou, and X. Zhao, "Properties of stability and Hopf bifurcation for a HIV infection model with time delay," Applied Mathematical Modelling, vol. 34, no. 6, pp. 1511-1523, 2010.

[19] E. Beretta and Y. Kuang, "Geometric stability switch criteria in delay differential systems with delay dependent parameters," SIAM Journal on Mathematical Analysis, vol. 33, no. 5, pp. 11441165, 2002.

[20] Z. P. Wang and R. Xu, "Stability and Hopf bifurcation in a viral infection model with nonlinear incidence rate and delayed immune response," Communications in Nonlinear Science and Numerical Simulation, vol. 17, no. 2, pp. 964-978, 2012.

[21] M. Ferrara, "An AK Solow model with a non-positive rate of population growth," Applied Mathematical Sciences, vol. 5, no. 25-28, pp. 1241-1244, 2011.

[22] M. Ferrara, "A note on the AK Solow-Swan model with bounded population growth rate," Applied Mathematical Sciences, vol. 5, no. 25, pp. 1235-1239, 2011.

[23] M. Ferrara, "An AK Solow model with logistic law technology," International Journal of Pure and Applied Mathematics, vol. 67, no. 3, pp. 337-340, 2011.

[24] S. L. Fang and M. H. Jiang, "Stability and Hopf bifurcation for a regulated logistic growth model with discrete and distributed delays," Communications in Nonlinear Science and Numerical Simulation, vol. 14, no. 12, pp. 4292-4303, 2009.

[25] Y. Enatsu, E. Messina, Y. Muroya, Y. Nakata, E. Russo, and A. Vecchio, "Stability analysis of delayed SIR epidemic models with a class of nonlinear incidence rates," Applied Mathematics and Computation, vol. 218, no. 9, pp. 5327-5336, 2012.

[26] Y. K. Xue and X. F. Duan, "The dynamic complexity of a Holling type-IV predator-prey system with stage structure and double delays," Discrete Dynamics in Nature and Society, vol. 2011, Article ID 509871, 19 pages, 2011.

[27] Y. K. Xue and X. Q. Wang, "Stability and local Hopf bifurcation for a predator-prey model with delay," Discrete Dynamics in Nature and Society, vol. 2012, Article ID 252437, 17 pages, 2012.

[28] Y. K. Xue and J. F. Wang, "Backward bifurcation of an epidemic model with infectious force in infected and immune period and treatment," Abstract and Applied Analysis, vol. 2012, Article ID 647853, 14 pages, 2012. 


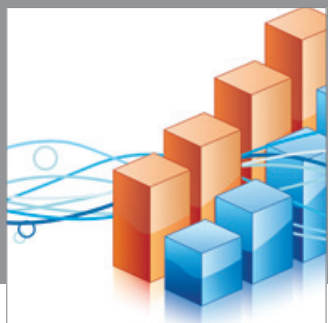

Advances in

Operations Research

mansans

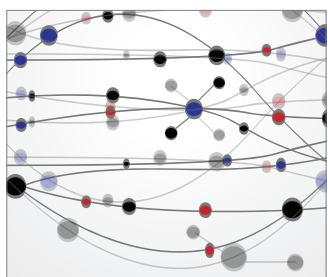

The Scientific World Journal
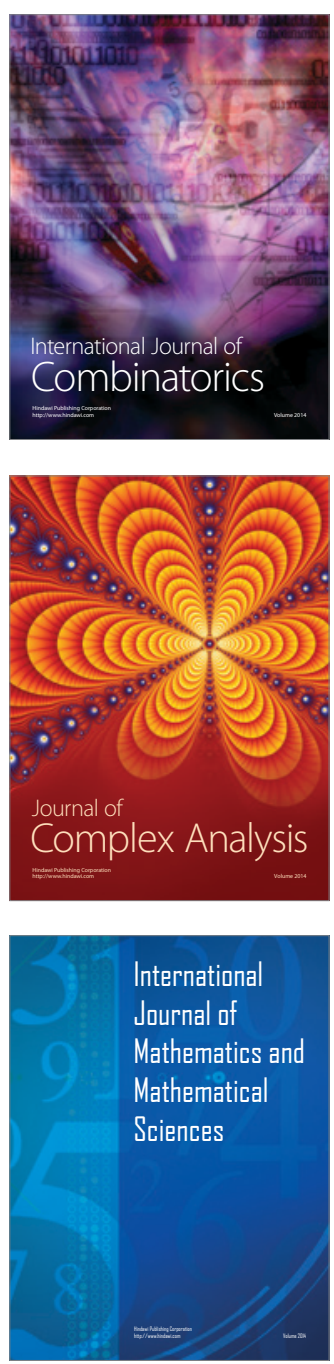
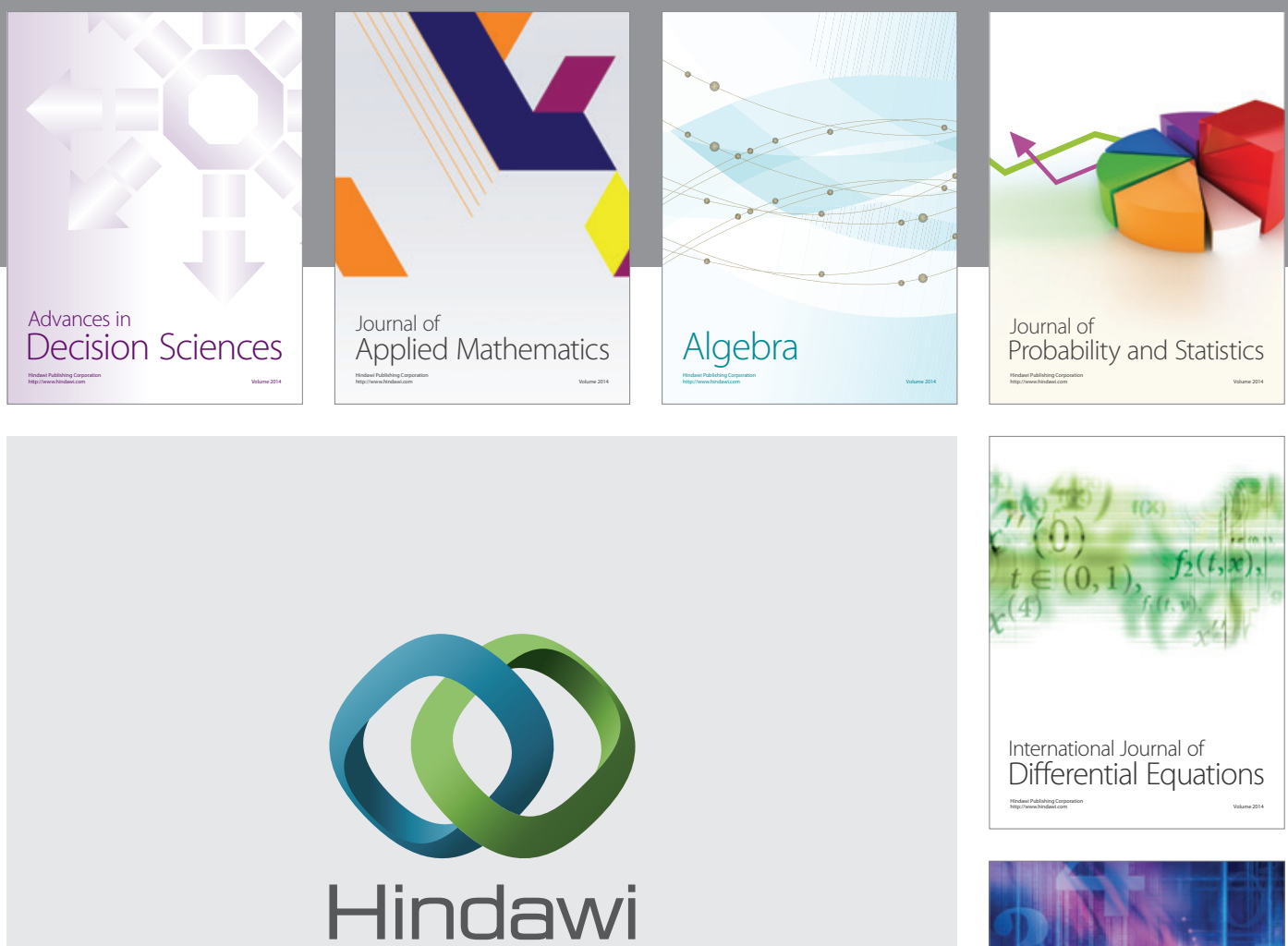

Submit your manuscripts at http://www.hindawi.com
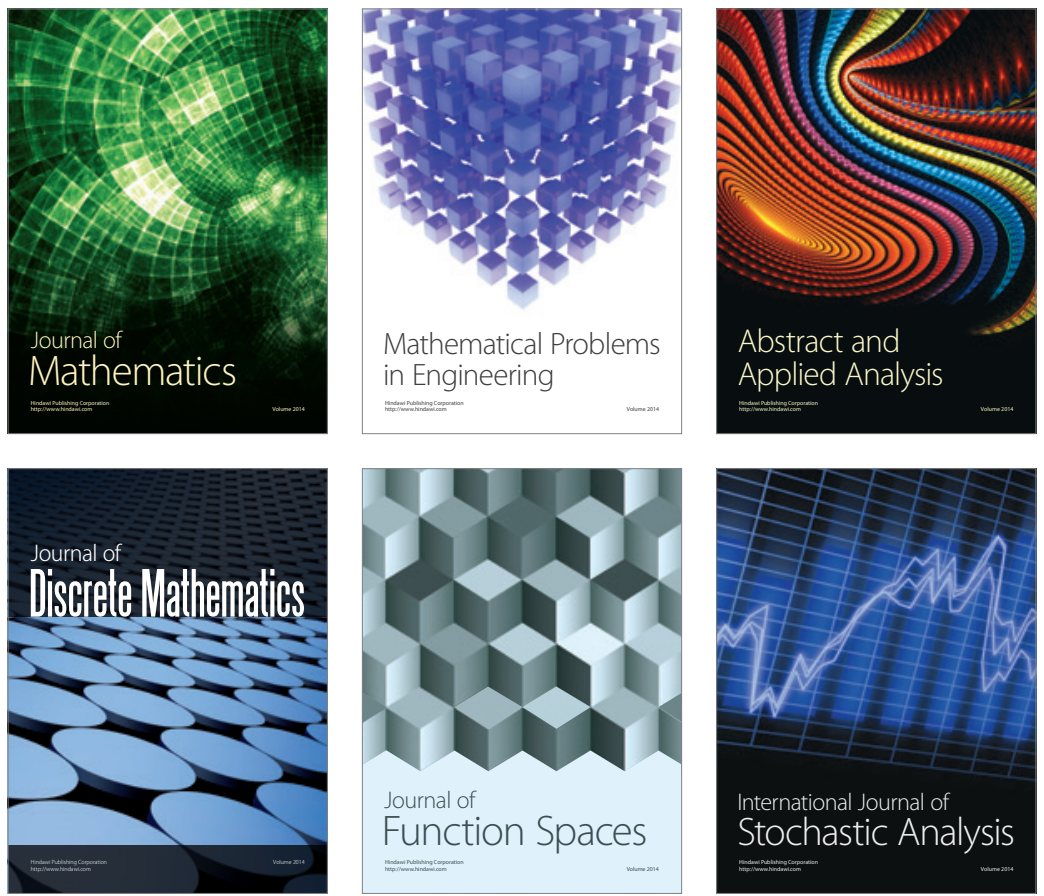

Journal of

Function Spaces

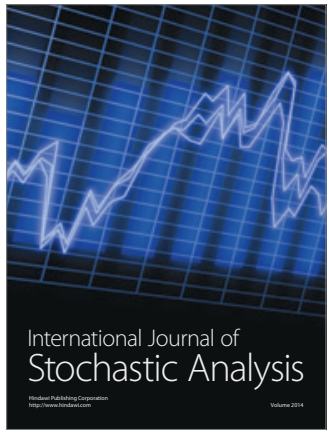

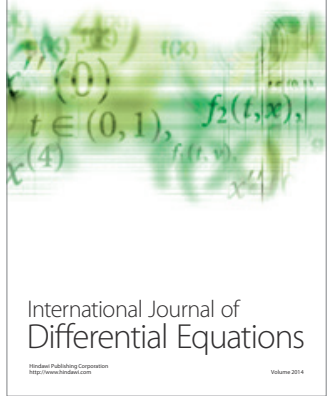
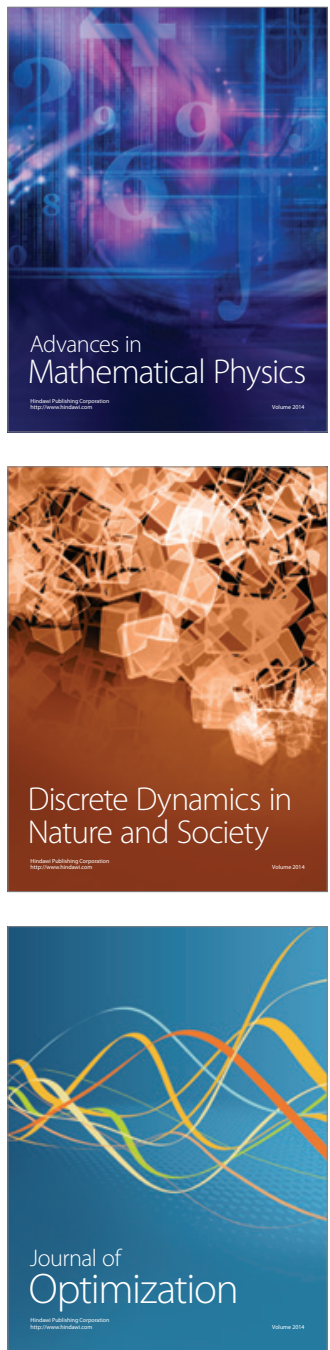